\title{
ON THE USE OF POLYCRYSTAL AND INDIVIDUAL ORIENTATION TEXTURE ANALYSIS METHODS FOR BCC MATERIALS
}

\author{
I.V. GERVASYEVA, B.K. SOKOLOV, A.K. SBITNEV \\ Institute of Metal Physics, Russian Academy of Sciences, \\ S. Kovalevskaya str. 18, 620219 Ekaterinburg, Russia
}

(Received 20 April 1995; in final form 20 July 1995)

\begin{abstract}
The reliability of the harmonic method of the ODF calculation from X-ray pole figures was estimated for cubic symmetry materials. For this purpose simulated textures with a preset scattering value of the components were used. Some examples using the Roe method to the study of the secondary recrystallization process in the $\mathrm{Fe}-3 \% \mathrm{Si}$ alloy are given. The capabilities of the etch-pits methods as the simplest discrete method used to determine the orientation density are discussed.
\end{abstract}

KEY WORDS: Roe method, Reliability of harmonic method, BCC metals, Etch-pits method.

\section{INTRODUCTION}

Both continuous and discrete methods are utilized for quantitative texture analysis. In the first case pole figures from X-ray or neutron diffraction data are used for the ODF calculation. Such an ODF could provide a high statistical reliability in describing the texture of the sample as a whole. But the ODF calculation from pole figures is associated with certain errors resulting solely from this method. Individual orientation methods use single orientations of grains or their structural elements determined using X-ray, electron or optical techniques. This makes it possible to ascertain orientation distributions both for the microtexture and for the texture as a whole. In the latter case, however, the statistics often proves to be insufficient.

Which method to use depends on the particular research problem. Thus, to predict properties, it is enough to know the strong texture components. To solve other materials science problems, we have to know the texture in full detail.

Figure 1 shows a large grain in oriented silicon steel with the Goss orientation $\{110\}$ $<001>$ growing during secondary recrystallization towards the fine-grain multicomponent matrix. The problem is what kind of grain boundary misorientation is favourable for survival of the secondary grains with the sharp Goss texture.

Individual orientations of large secondary grains (2, Figure 1) can be determined by any individual orientation method.

To describe in detail the fine-grained multicomponent matrix (1, Figure 1), it is necessary to know the orientation distribution function. In this respect the polycrystal diffraction methods are very appropriate because they give good statistics, which is important to characterize the texture of a layer of a sample or of a sample as a whole. 


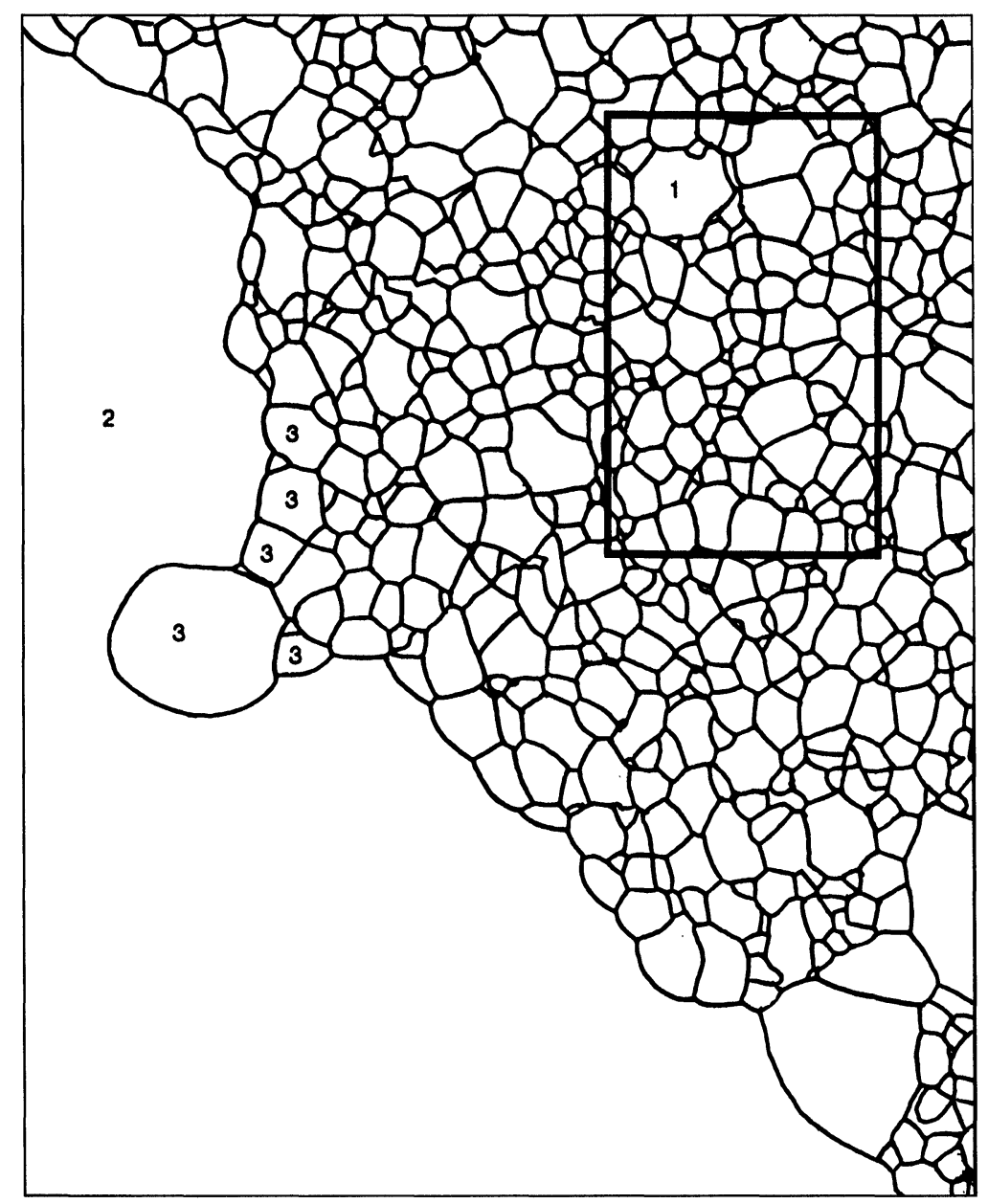

Figure 1 The structure of materials during secondary recrystallization and methods used for analysis of grain orientations: 1 harmonic method of ODF calculation; 2,3 etch-pits method, EBSP

Other requirements to texture analysis methods should be considered if one wishes to estimate the misorientation at the front of a growing secondary grain (3, Figure 1). In this case the use of local techniques of orientation measurements is necessary. If such data on single orientations are available, we can examine, for example, ODF variation at the front of growing grains during secondary recrystallization. The electron back scattering pattern method, the etch-pits method and some other methods can serve as local techniques.

This paper discusses the potentialities of the Roe method for the ODF calculation and those of the etch-pits technique for the study of texture transformations in cubic materials. 


\section{ANALYSIS OF THE RELIABILITY OF THE HARMONIC METHODS}

In recent years a lot of papers has appeared to demonstrate shortcomings of the harmonic methods of ODF inversion (Matthies, 1979; Lucke et al., 1981). Alternative methods for ODF calculation have been suggested (Matthies, 1987; Jura, 1990), but they either are too complicated or produce other distortions in the ODF, for example, the method of texture function modelling by discrete gaussian distributions. No doubt, the neglection of odd coefficients brings certain errors to ODF (reduced ODF), but the gravity of these errors depends on many factors, such as the crystal symmetry, texture sharpness, the number of terms of series expansion, and the accuracy of the pole figure measurement. The last two factors must correlate with each other to obtain good results.

In our program the (reduced) ODF is calculated according to the Roe formalism from three complete pole figures. Pole figures are measured by combining transmission and backreflection measurements with Mo-radiation with a step of $3^{\circ}$. In order to increase the diffraction area the sample is scanned, the time of counting is 10 seconds. This is especially important for recrystallized samples, because the poor statistics causes a distortion of the orthorhombic symmetry. The ODF is calculated with expansion into series, the number of terms being 22 , using even orders only.

When such ODF calculation method was used by us for the study of texture transformation in BCC metals, it was subject to numerous tests.

The reliability of the method and the dependence of the magnitude of errors upon the texture sharpness were estimated by calculating ODF for simulated single- and multicomponent textures with a preset scattering of the components.

The scattering was given by the gaussian distribution on pole figures and then the ODF was calculated from the pole figures as though the figures were experimental ones.

On the example of the single component texture $\{110\}<001>$ with spread about the ideal component of 10 and $30^{\circ}$, we can see that with an increase in scattering the negative and false peaks decrease greatly (Figure 2). For the texture with a $10^{\circ}$ scattering the error runs into 20 times random and is $15 \%$ of the true maximum. For the $30^{\circ}$-scattering the error and the random level are nearly the same and the error is over $10 \%$ of the true maximum. The texture scattering above the error level corresponds to the given one.

The error also decreases, if the ODF is calculated for a multicomponent texture containing components with a $10^{\circ}$-scattering.

To determine the possibility of estimating the presence of a weak component in the texture, four- and five-component textures were simulated. The maximum of the pole density of one of the components was lower than that of the others (Table 1).

The given components are typical components of deformation and recrystallization textures in BCC metals. In the ODF section $\emptyset=45^{\circ}$ (Figure 3) we can see "ghosts" in the range of angles $\Theta$ near $90^{\circ}$. Probably these "ghosts" are tails of strong components in the range of angles $\Theta$ near $55^{\circ}$. They are on this line that the given weak component is found.

The given pole density parameters were taken to calculate true volume fractions of the texture components. They were compared with the volume fractions calculated from the ODF data. The values show a good agreement (Table 1). Note that in estimating the amount of the weak component we can avoid the influence of "ghosts" by using an alternative angular range of the Euler space with an equivalent set of orientations. 

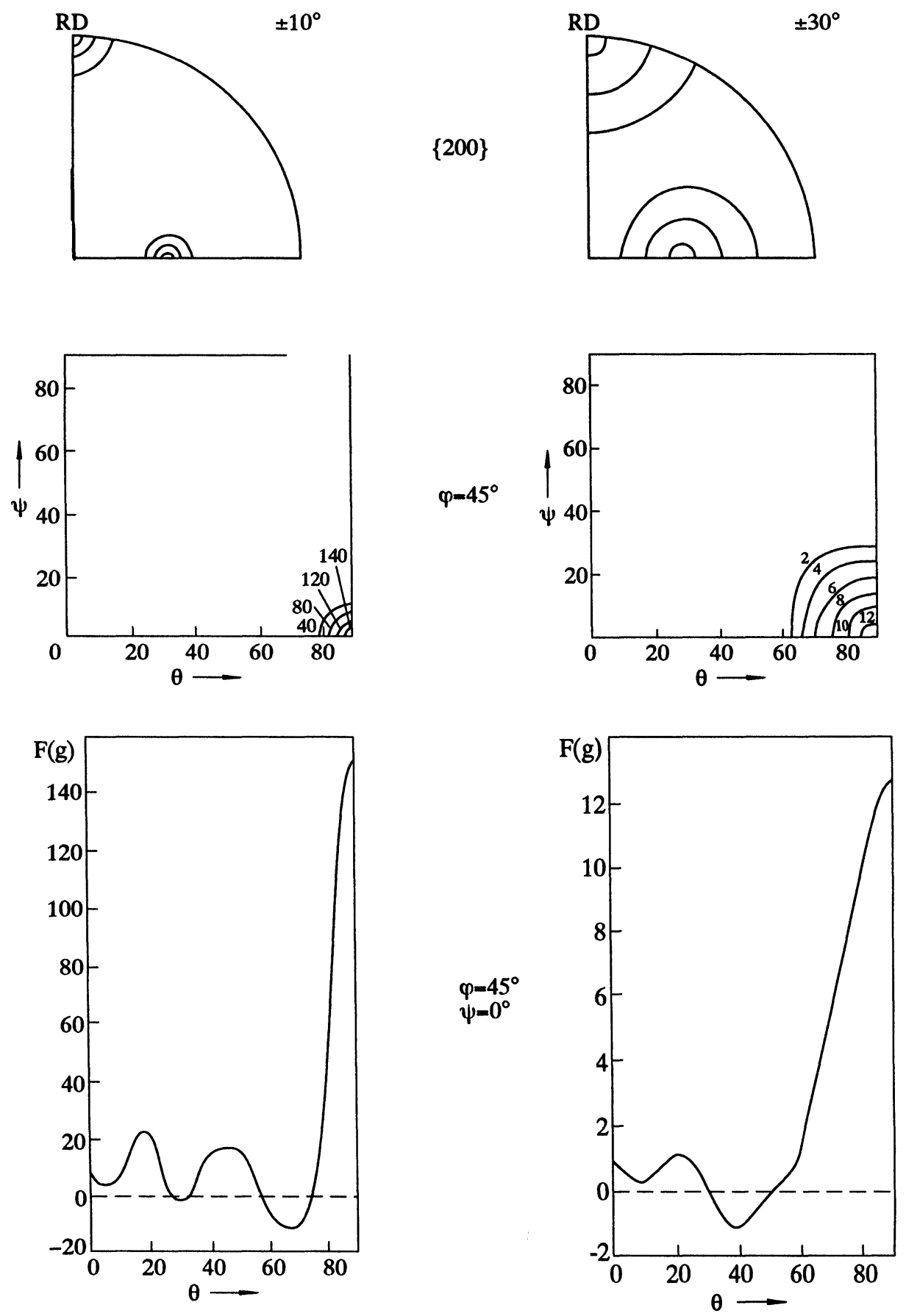

Figure 2 Single-component texture with different scattering about the $\{110\}<001>$ orientation. 
Table 1 Volume fractions of the components $\left(10^{\circ}\right.$-scattering $)$ in simulated textures

\begin{tabular}{|c|c|c|c|c|c|}
\hline \multirow{2}{*}{$\begin{array}{c}\text { Texture } \\
\text { composition }\end{array}$} & \multicolumn{2}{|c|}{ Component } & \multirow{2}{*}{$\begin{array}{c}\text { The peack of a } \\
\text { pole density, } \\
\text { relative units }\end{array}$} & \multicolumn{2}{|c|}{$\Delta V / V, \%$} \\
\hline & $\{h k l\}$ & $\langle u v w\rangle$ & & $\begin{array}{c}\text { over the pole } \\
\text { density }\end{array}$ & over the $O D F$ \\
\hline \multirow[t]{4}{*}{1} & 111 & 112 & 10 & 31.8 & 28.8 \\
\hline & 111 & 110 & 10 & 31.8 & 28.8 \\
\hline & 112 & 110 & 10 & 31.8 & 28.8 \\
\hline & 110 & 001 & 3 & 4.7 & 4.4 \\
\hline \multirow[t]{5}{*}{2} & 111 & 112 & 10 & 27.4 & 24.3 \\
\hline & 111 & 110 & 10 & 27.4 & 24.3 \\
\hline & 112 & 110 & 10 & 27.4 & 24.3 \\
\hline & 100 & 001 & 10 & 13.7 & 15.7 \\
\hline & 110 & 001 & 3 & 4.0 & 4.1 \\
\hline
\end{tabular}
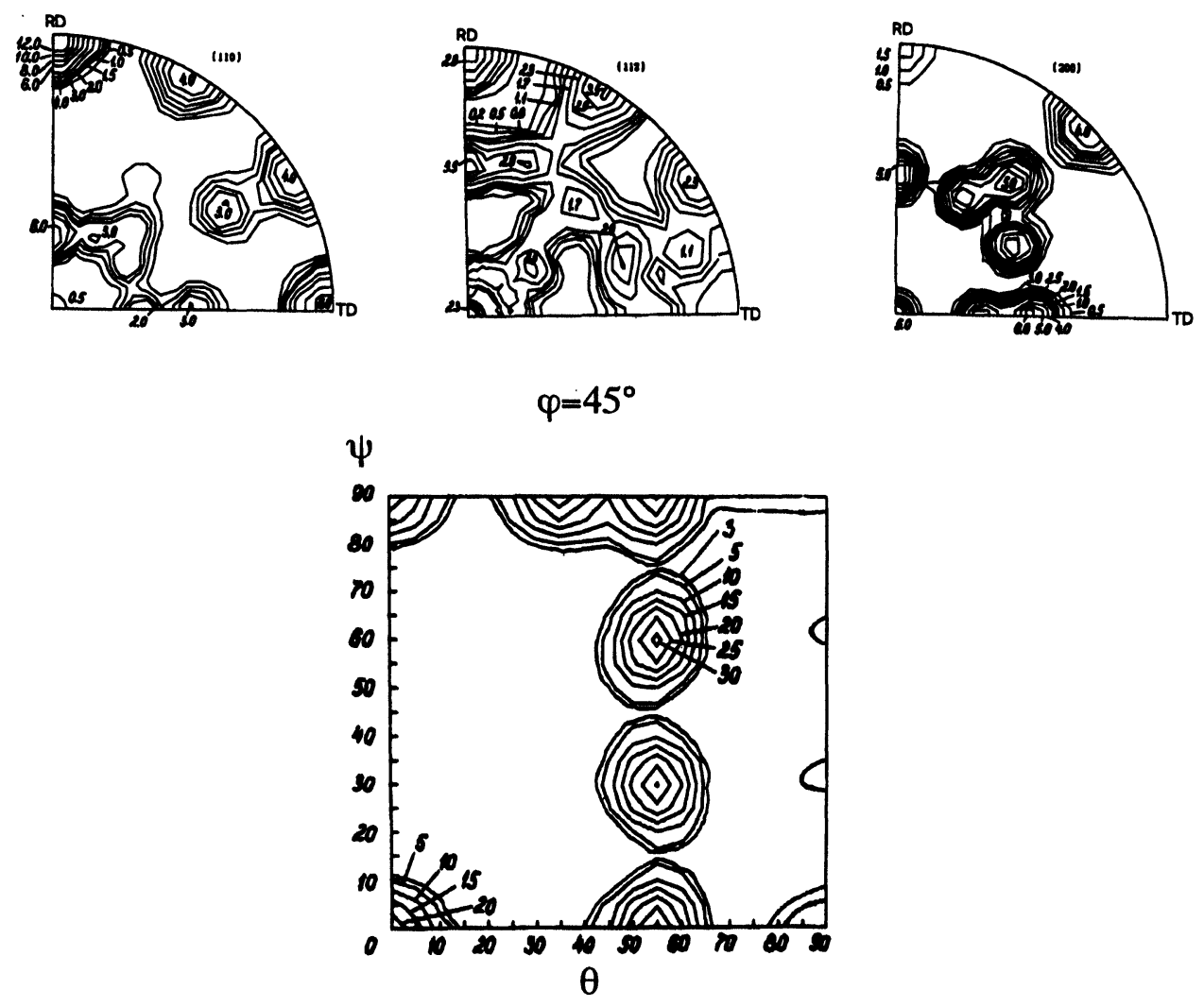

Figure 3 Five-component texture. Scattering of the component is $\pm 10^{\circ}$. Experimental pole figures and ODF section. 
The volume fraction of the $\{110\}<001>$ component can be determined not over all regions of the component in the ODF representation (1,2,3 in Figure 4) but over one region ( 1 in Figure 4$)$ by taking the product of the corresponding coefficient.

Real multicomponent textures are much more scattered and the error in the ODF calculation should be smaller. In this case the error was estimated by comparing the experimental and calculated pole densities. For the deformation and recrystallization textures of polycrystalline electrical steel the average misfit did not exceed $5 \%$.

To verify correctness of the ODF reproduction from pole figure data, the problem was examined for stability (Gervasyeva and Zhigalin, 1985). To this end, the experimental ODF was compared with the ODF calculated from the pole densities, which were varied randomly within the limits of the measurement error (Figures $5 \mathrm{a}$ and $5 \mathrm{~b}$ ). As can be seen, the variation does not lead to a considerable change in ODF when the number of series terms is 22 . It was specially shown for the weak component that random distortions of the pole density up to $20 \%$ do not cause a variation of ODF values in excess of $5 \%$ (Figure $5 \mathrm{c}$ ).

In addition to these estimates, we compared the ODF calculated from the same pole figures data at four research centers in Russia, where different programs by Bunge or Roe are used (Alexandrov et al., 1993). Though each program is specific in ODF calculation, as a whole the texture pattern exhibits a close coincidence.

When the EBSP method was introduced, a natural idea was conceived to use the method for estimating drawbacks of the ODF calculation from polycrystal diffraction data resulting from the absence of the odd part. This work was done by Penelle et al. (1991). It was shown that for textures, which are not too sharp, the ODF determined by X-ray diffraction is in good agreement with the full ODF found from the EBSP data.

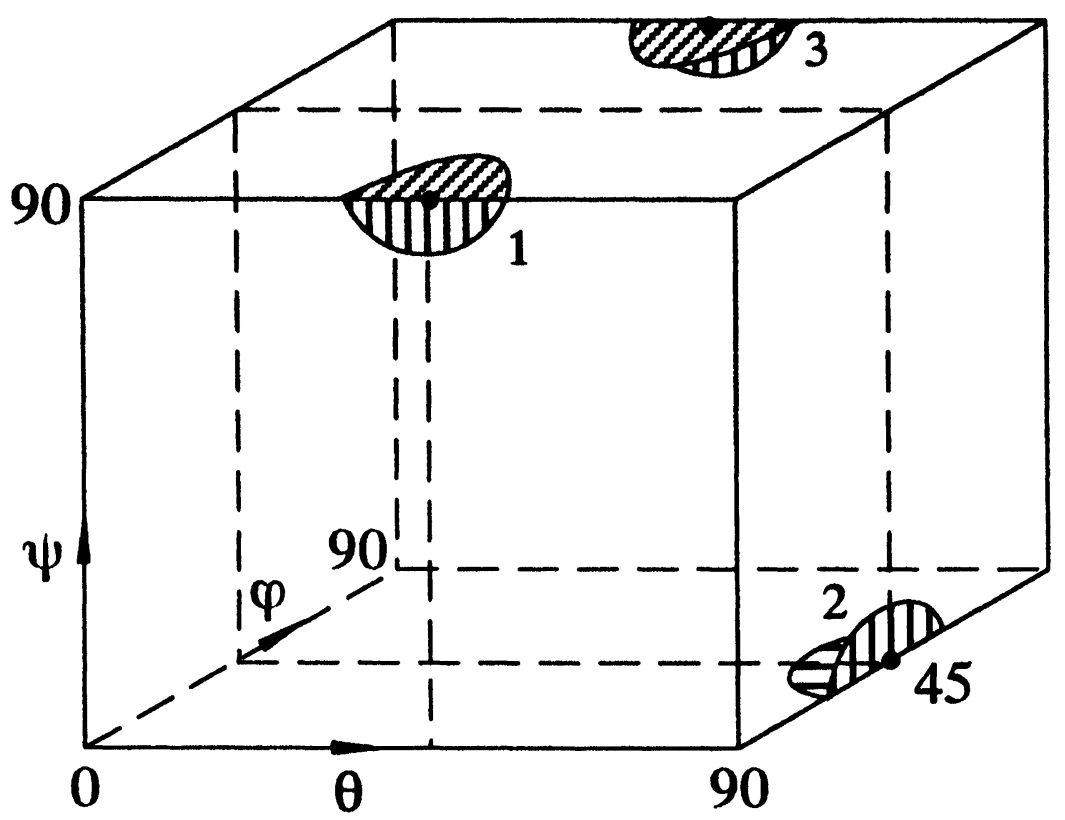

Figure 4 Location of the $\{110\}<001>$ orientation in the Euler space. 


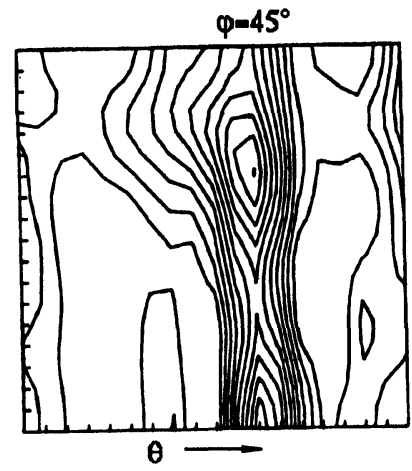

a

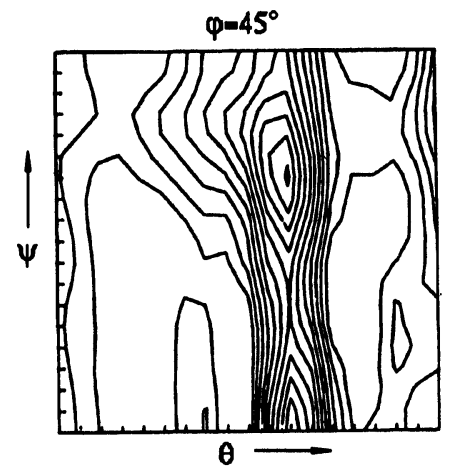

b

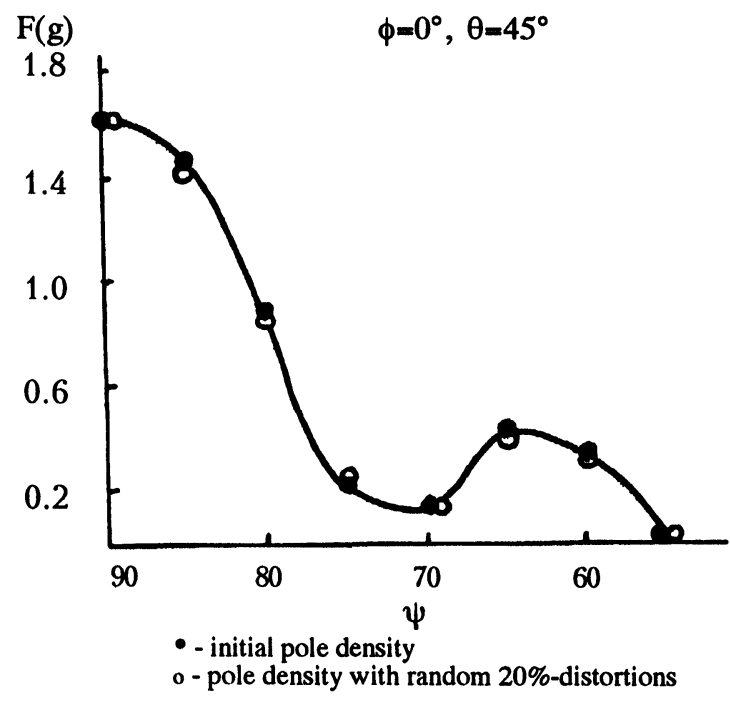

c

Figure 5 Solution stability in the problem of the ODF reproduction:

a) initial ODF;

b) ODF from the pole density with random distortions within the measurements error (10\%);

c) ODF near the weak $\{110\}<001>$ orientation.

\section{ANALYSIS OF TEXTURE TRANSFORMATION IN Fe-3\% Si USING THE HARMONIC METHOD OF ODF CALCULATION}

Taking silicon steel as an example, it is possible to show how the sharpness of the cube-on-edge texture, which is formed during the secondary recrystallization, can be predicted using the quantitative analysis of the primary recrystallization texture. Besides that, in order to exclude oriented nucleation, the technique of artificial secondary recrystallization was use. The scattering of the cube-on-edge texture was characterized by the root-mean-square deviation from the ideal orientation about the normal direction to the rolling plane. 
A different composition of the primary recrystallization texture was produced thanks to different pretreatment procedures (Figure 6). Volume fractions of certain orientations of the investigated texture were calculated (Table 2). Two of them, $\{111\}<112\}$ and $\{113\}<361>$, were considered as the components favourable for the growth of cubeon-edge grains, and the third one, $\{100\}<011>$, was assumed to be unfavourable.

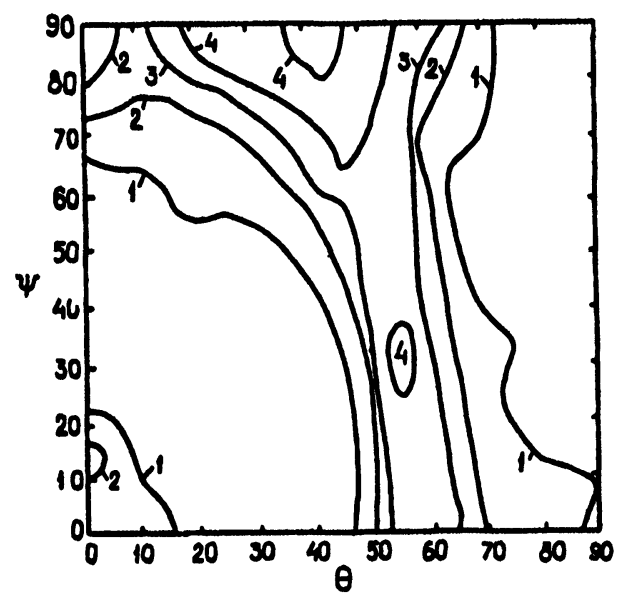

a

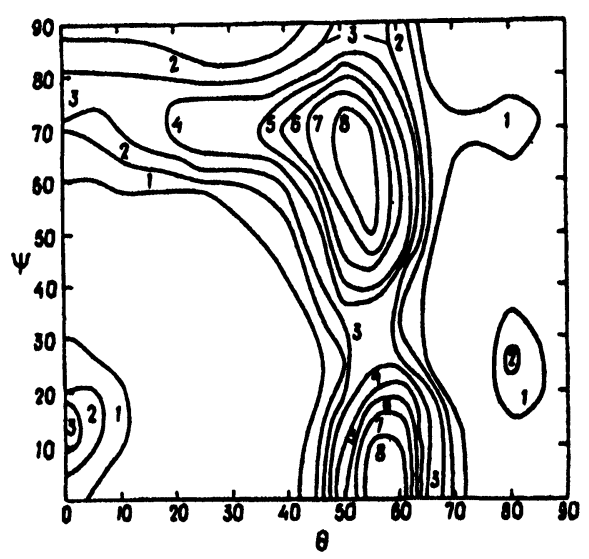

c

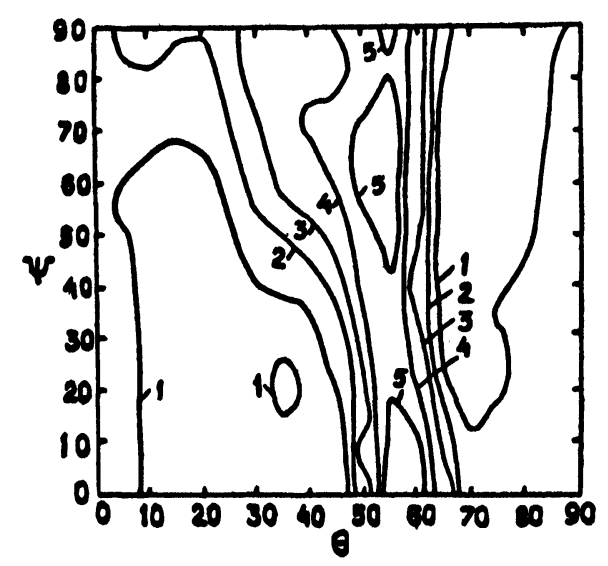

b

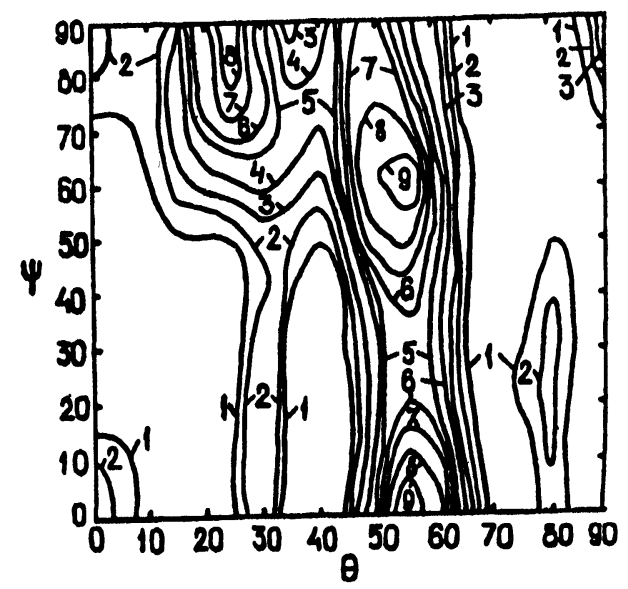

d

Figure 6 Different primary recrystallization textures in Fe-3\% Si (Section $\varphi=45^{\circ}$ ):

a) two-stage cold rolling, $70 \%$ and $50 \%$;

b) cold rolling, $70 \%$;

c) cold rolling, $90 \%$;

d) cold rolling, $90 \%$ at $\pm 30^{\circ}$ to the hot rolling direction. 
Table 2 Volume fractions of the grains near the ideal orientations $\left( \pm 12,5^{\circ}\right)$ in recrystallized samples

\begin{tabular}{lccc}
\hline Rolling treatment & $\{111\}<112>$ & $\begin{array}{c}\Delta V / V, \% \\
\{113\}<361>\end{array}$ & $\{100\}<011>$ \\
\hline Two stage cold rolling 70 and 50\% & 9.8 & 11.4 & 4.6 \\
Cold rolling 70\% & 11.2 & 13.3 & 4.2 \\
Cold rolling 90\% & 17.9 & 17.5 & 3.8 \\
Cold rolling 90\% along $\pm 30^{\circ}$ to hot RD & 13.2 & 27.4 & 1.3 \\
\hline
\end{tabular}

It was found that the ratio of favourable and unfavourable orientations determines the scattering of the cube-on-edge texture (Figure 7). An increase in this ratio leads to a rise in sharpness of the secondary recrystallization texture.

So, as a matter of experience, the harmonic method, which uses polycrystal diffraction data, can be considered as quite applicable to the quantitative analysis of the texture of cubic materials. One can say that it has become a common classical method of texture analysis as for a long time has been the pole figures method.

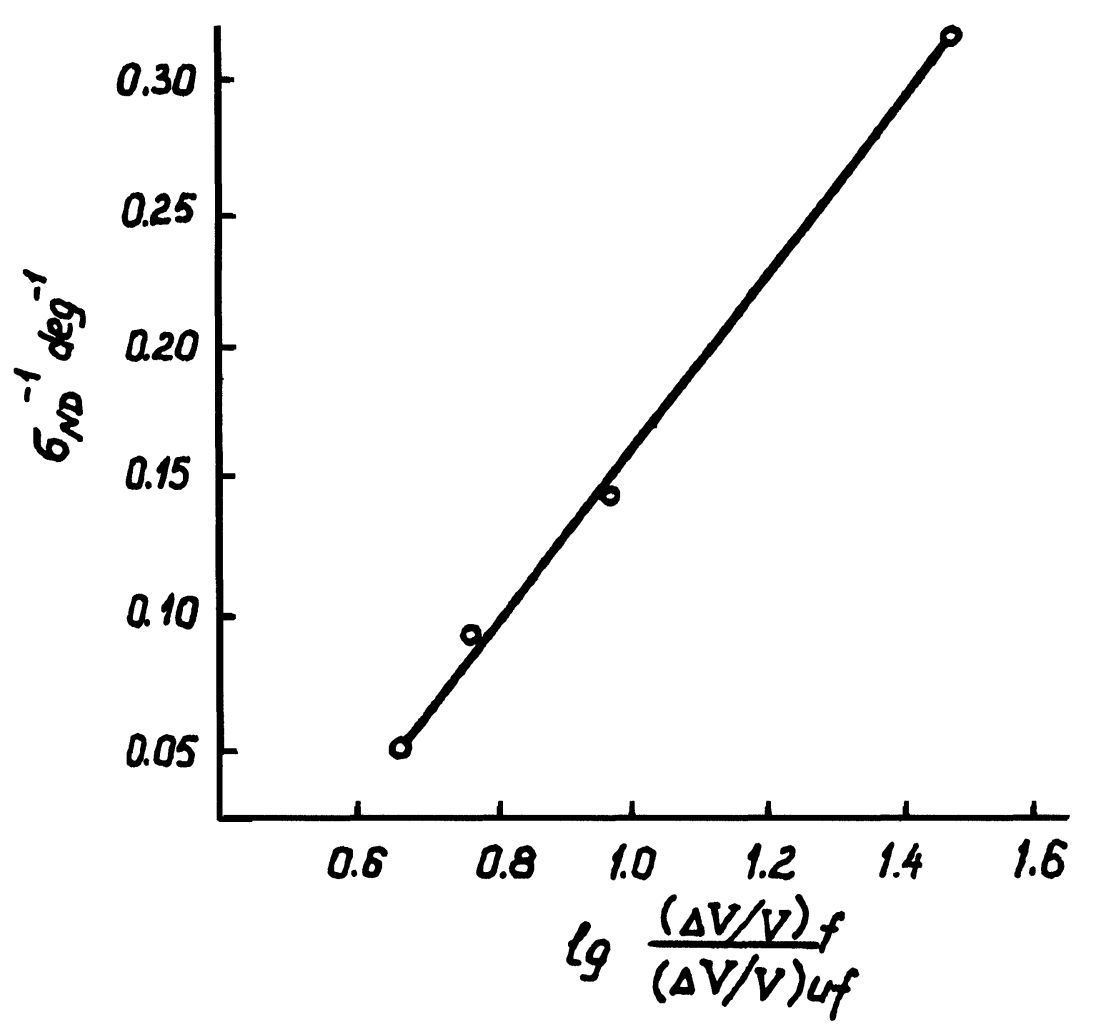

Figure 7 Effect of the matrix texture composition upon the sharpness of the "cube-on-edge" texture. 


\section{REFINEMENT OF THE ETCH-PITS METHOD FOR ASCERTAINING SINGLE ORIENTATIONS OF THE PRIMARY RECRYSTALLIZATION GRAINS}

As far as single orientation methods are concerned, the EBSP technique and orientation imaging microscopy surely have extensive potentialities (Adams et al., 1993). Unfortunately, not every laboratory has the corresponding equipment at its disposal. Probably, because of too expensive equipment for EBSP, alternative methods of local orientation measurements keep being developed. The etch-pits methods is one of them. It is based on the development of flat-face pits when the sample's surface is etched. Grain orientations are detected by the disposition of the faces and their intersection lines.

Although this simple method ranks below the above-mentioned new discrete technique, a lot of problems is solved by the method. In this paper we show how to improve the accuracy of orientation measurements and to compute the angles of orientation space.

There are two ways of orientation determination by etch-pits. In the first way, the dimensions of flat-pit intersection lines and the angles between these lines are determined from the microscope photograph. Equations relating these parameters and Miller indices have been derived (Sokolov, 1969). In the studies due to Termer and Goldstein (1987) and Lee et al. (1993) the relation between the etch-pit parameters and Euler angles was established. Here the accuracy depends on the preparation of the sample's surface and the production conditions of etch-pits.

In the second way, orientations are determined using an optical goniometer. With this device, the angles of pit-face space arrangement are registered by focussing on maximum brightness. The accuracy of this method greatly depends on the conditions of etch-pit emergence.

The first method offers an advantage in the area resolution, but it is inferior in the orientation error (about $2-15^{\circ}$ depending on the pit pattern). With the other method the area resolution is about $50 \mu \mathrm{m}$ if a two-circle goniometer with a magnification of 40 times is used. The investigated area can be decreased to $10 \mu \mathrm{m}$ if a goniomicroscope is used (Table 3).

The type of etch-pits depends on the reagent used. Usually in ferrous alloys one tries to produce etch-pits composed of cube planes. The accuracy of the orientation determination can be raised through the use of etch-pits composed of two systems of crystallographic planes $\{100\}$ and $\{110\}$ (Figure 8). Such cut allows one to perform more measurements, namely 5-7 (against 2-3 measurements when only cube planes are used). The increase in the number of measurements narrows the confidence interval for the orientation angles determined and decreases the root-mean square error.

Table 3 Different patterns of the etch-pits method

\begin{tabular}{lccc}
\hline Instruments & $\begin{array}{c}\text { Highest spatial } \\
\text { resolution }\end{array}$ & $\begin{array}{c}\text { Angular resolution } \\
\text { (degrees) }\end{array}$ & Authors \\
\hline Optical microscope & $10 \mu \mathrm{m}$ & $2-15$ & Lee et al., 1994 \\
Optical microscope & $10 \mu \mathrm{m}$ & $2-15$ & Termer and Goldstein, 1987 \\
Optical Goniometer & $50 \mu \mathrm{m}$ & 2 & Sokolov, 1969 \\
Gonio-microscope & $10 \mu \mathrm{m}$ & 1 & Taoka et al., 1965 \\
\hline
\end{tabular}




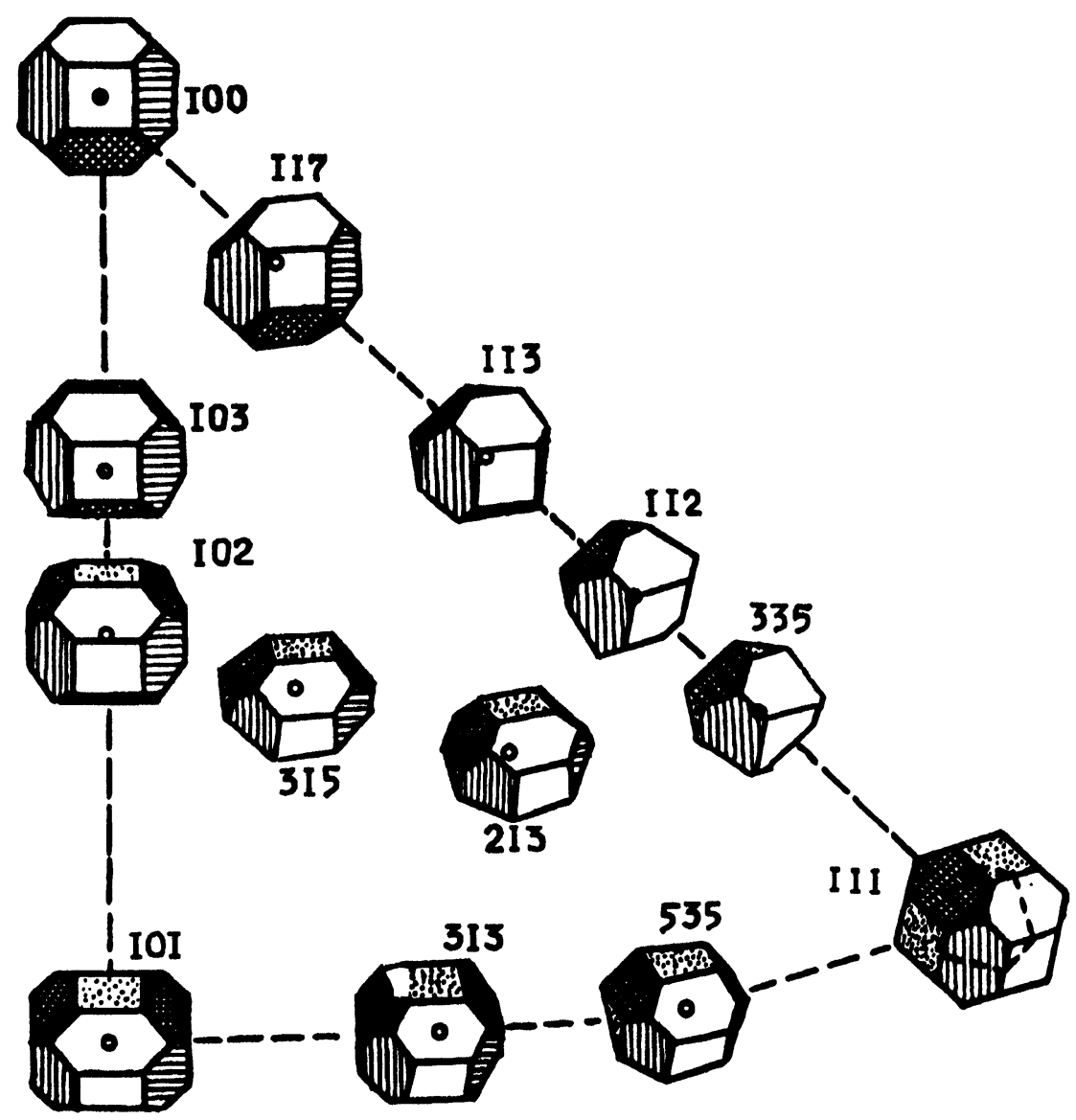

Figure 8 Etch-pits patterns for different orientations of the sample's surface. Etch-pits are composed of $\{100\}$ and $\{110\}$ planes.

So, with 5 measurements per each area element the error is about $2^{\circ}$. This double cut of pits is produced in the following etching agent: $74 \% \mathrm{H}_{2} \mathrm{O}, 24 \% \mathrm{H}_{2} \mathrm{O}_{2}, 2 \% \mathrm{HCl}$.

In our software for the calculation of orientations, polar angles corresponding to the goniometer indications serve as the input data. At the output we have orientations in Miller indexes or in Euler angles. Besides that, the software allows the determination of misorientation parameters for any orientation. This is convenient for studying the orientation-dependent grain growth rate in some materials-science processes.

\section{CONCLUSIONS}

For a certain symmetry of crystals and for certain research problems the Bunge-Roe method is quite adequate and there is no need to use other methods which cause other distortions. 
Other methods of quantitative texture analysis are needed when solving specific research problems such as microtexture study.

The etch-pits method refined in terms of accuracy and resolution can be successfully applied to tackle many materials science problems.

\section{References}

Adams, B. L., Dingly, D. J., Kunze, K. and Wright, S. J. (1993). Orientation Imaging Microscopy: New Possibilities for Microstructural Investigations Using Automated BKD Analysis. Proceedings of the 10th International Conference on Textures of Materials ICOTOM 10. Ed. H.J. Bunge. Trans Tech Publications Ltd, Germany-Switzerland, 31-42.

Alexandrov, I. V., Gervasyeva, I. V., Gnesin, B. A., Ketov, S. P. and Kurtasov, S. F. (1993). The Comparison of the Results of the ODF Calculation from Non-ideal Pole Figures in Different Laboratories. Zavodskaya laboratoriya, N 4, 38-41.

Gervasyeva, I. V. and Zhigalin, A. G. (1985). Some Ways of the Accurasy Estimation of the ODF Texture Analysis for Cubic Materials. Zavodskaya laboratoriya, v. 51, N 3, 38-40.

Jura, J. (1990). On the Model Representation of the Texture Components in FCC and BCC Metals. Proceedings of the XIYth Conference on Applied Crystallography. Ed. Z. Bojarski, J. Paduch, H.Krzton, Silesian University, Poland, 66-71.

Lee, K. T., deWit, G., Morawiec, A. and Szpunar, J. A. (1993). The Application of the Etch-pits Method to Quantitative Texture Analisis. Mater. Sci. and Tech. (to be published).

Lucke, K., Pospiech, J., Virmich, K. H. and Jura, J. (1981). On the Problem of the Reproduction of the True Orientation Distribution from Pole Figures. Acta Met., v. 29, 1, 167-185.

Matthies, S. (1979). On the Reproducibility of the Orientation Distribution Function of Texture Samples from Pole Figures (Gost Phenomena). Phys. Status Solidi (B), v.92, N 2, K135-K138.

Matthies, S. (1987). On the Basic Elements of and Practical Experience with the WIMV algorithm and ODF Reproduction Method with Conditional Ghost Correction. Proceedings of the Eighth International Conference on Textures of Materials ICOTOM 8. Ed. J.S.Kallend and G.Gottstein. The Metallurgical Society, Inc, USA, 37-48.

Penelle, R., Baudin, T., Paillard, P. and Mora, L. (1991). Characterization of Recrystallization Textures in $\mathrm{Fe}-3 \% \mathrm{Si}$ sheets by EBSP: Comparison with X-Ray Diffraction. Proceedings of the Ninth International Conference on Textures of Materials ICOTOM 9. Ed. H.J. Bunge. In: Textures and Microstructures (Special Issue), v. 14-16, 597-610.

Sokolov, B. K. (1969). Optical Method for Grain Orientation Determination in Transformer Steel. In: Struktura I svoistva teksturovannich metallov I splavov. Moskva, Nauka, 112-127.

Taoka, T., Furubayashi, E. and Tageuchi, S. (1965). "Gonio-Microscope" and its Metallurgical Applications. Trans. Nat. Res. Inst. Metals, v.7, N 2, 67-74.

Termer, E. R. and Goldstein, V. Ya. (1987). ODF Reproduction from Etch-pits Pattern. Zavodskaya laboratoriya, N 5, 18-22. 